\title{
Heterozygote deficiency and chimerism in remote populations of a colonial ascidian from New Zealand
}

\author{
R. Ben-Shlomo*, J. Douek, B. Rinkevich \\ National Institute of Oceanography, Israel Oceanographic and Limnological Research, Tel Shikmona, PO Box 8030, \\ Haifa 31080, Israel
}

\begin{abstract}
Botryllus schlosseri, presumably a Mediterranean tunicate that became a worldwide distributed species, has colonized New Zealand islands during the last 2 centuries. Genetic diversity of 6 populations was tested by 5 polymorphic microsatellite loci ( 4 to 20 alleles per locus). Allele distribution patterns at all loci are characterized by a few major and many rare alleles, suggesting a founder effect. B. schlosseri populations in the North and South Islands differ considerably in allele distribution, pointing to different founders and limited gene flow. A Hardy-Weinberg exact test for all loci and all New Zealand populations reveals a significant heterozygote deficiency, suggesting partial inbreeding as a result of an aggregated settlement of sibling B. schlosseri tadpoles. Natural chimeras (colonies expressing more than 2 alleles per individual at a locus) are found in most localities. Underestimated levels of chimerism are surprisingly high (an average of $8 \%$ ), reaching $14 \%$ in the South Island. Comparisons with Californian and Israeli populations further support the generally accepted dogma that B. schlosseri is of a Mediterranean Sea origin, and suggest different founders for New Zealand and Californian coasts.
\end{abstract}

KEY WORDS: Botryllus schlosseri · Biological introduction · Cosmopolitism · Chimerism · Heterozygote deficiency $\cdot$ Microsatellite

Resale or republication not permitted without written consent of the publisher

\section{INTRODUCTION}

Introduction of non-indigenous species into foreign habitats is an inevitable consequence of human activities. Man-mediated dispersal mechanisms (such as ballast water, rafting on boat hulls or floating objects, etc.) provide opportunities for more species to become cosmopolitan. Successful introductions are particularly likely in marine organisms with numerous larvae and extended planktonic stages (Bastrop et al. 1998). Over the past decades, numerous aquatic invasions have occurred (Carlton \& Geller 1993). Invading, nonindigenous species probably have definable genetic characteristics in common that may be generalized by

\footnotetext{
*E-mail: rachel@ocean.org.il
}

careful comparison between different populations of the same species (Gray 1986).

The cosmopolitan ascidian Botryllus schlosseri, a shallow-water sedentary marine invertebrate, is globally distributed from polar regions to the tropics (Berrill 1950). This species, most likely of Mediterranean Sea origin (Berrill 1950), became a worldwide distributed tunicate mainly by transportation of colonies attached to the bottoms of ships (Berrill 1950, Skerman 1960). B. schlosseri colonies are found in very shallow water to almost $200 \mathrm{~m}$ depth, above and under stones, on algae and seaweeds, on pilings, floats, and other artificial substrata, within marinas and in the wild. It is, therefore, of great interest to analyze the genetic structure of B. schlosseri populations, especially in remote localities, to further reveal evolutionary-ecological facets of this successfully introduced species. 
One of the most distant Botryllus schlosseri populations is found along the North and South Island coasts of New Zealand (Ralph \& Harley 1952, Skerman 1960, Poore 1968, Luckens 1976, Millar 1982). Colonies residing in the shallow waters of New Zealand are morphologically indistinguishable from those of the Mediterranean, or the eastern and western Atlantic coasts (Millar 1982, B. Rinkevich unpubl. data). The first recorded European explorer to visit New Zealand was the Dutch seaman Abel Tasman, who briefly sailed along the west coast in 1642. The first European to actually land on New Zealand soil was the English explorer Captain James Cook in 1769. However, the onset of intensive European settlement can be traced back only to 1840 . Therefore, the introduction period of B. schlosseri to New Zealand coasts should be no longer than $230 \mathrm{yr}$ and probably less than $150 \mathrm{yr}$ ago. Thereafter, B. schlosseri has spread widely in both the North and the South Islands and has been reported in New Zealand since 1928 (van Name 1945, Lambert \& Lambert 1998).

The aim of this study was to genetically characterize these remote, newly established, yet geographically widespread populations of Botryllus schlosseri in New Zealand. We analyzed patterns of genetic diversity among 6 populations in both the North and South Islands, by the use of 5 microsatellite loci. A recent study on allele frequencies at a single microsatellite locus of 3 closely situated Mediterranean populations (Paz 1999) along the Israeli coast revealed a highly polymorphic locus with more than 60 alleles. Stoner et al. (1997) found only 17 alleles at the same locus in a recently (<60 yr old: Lambert \& Lambert 1998) introduced population from Monterey Marina, California, USA. The Californian population is regarded as younger than the New Zealand population, yet it is situated less peripherally within the B. schlosseri geographical distribution range. This may have resulted from continuous introductions within a shorter period of time. Lambert \& Lambert (1998) suggested that this species was introduced into Californian waters by oyster mariculture, as it appeared at oyster farms. A detailed comparison study between worldwide B. schlosseri populations, therefore, may serve as a very efficient tool for the genetic characterization of a successful invasive marine species.

\section{MATERIALS AND METHODS}

Sampling. Colonies (195) of Botryllus schlosseri were collected from shallow waters of New Zealand within marinas and harbors ( 0.5 m depth) during winter (June to July) 1997. Six populations were sampled, 5 in the North Island (145 colonies), ranging from Tutukaka in the north to Wellington in the south (Fig. 1), and 1 in Lyttelton (50 colonies) in the South Island. In 2 North Island localities (New Plymouth, Napier) and 6 harbors in the South Island (Akaroa, Timaru, Dunedin, Port Chalmers, Invercargil, Bluff) no colonies were found during this study in shallow water. A few colonies, however, were observed on algal holdfasts at $10 \mathrm{~m}$ depth from Portobello Marine Station, but were not included in the analysis. Sampled colonies grew at least $1 \mathrm{~m}$ apart.

Botryllus schlosseri colonies grow on and underneath floating docks, and on submerged ropes and other artificial hard substrates. Sampled colonies were peeled off the substrate, using single-edge razor blades and placed in a 11 container with fresh seawater. Great care was taken to sample colonies that did not show any morphological sign of chimerism (colonies with mixed colors or those characterized by intracolony variations in color morphs). From each colony, a tissue sample containing up to 20 zooids was taken for DNA extraction.

DNA extraction. Samples from the field were placed, separately, into $1.5 \mathrm{ml}$ vials containing $240 \mu \mathrm{l}$ lysis buffer (Graham 1978), homogenized, and extracted with $240 \mu \mathrm{l}$ phenol/chloroform. The material was shipped to the laboratory in Israel, where DNA isolation was completed by additional phenol/chloroform and chloroform extraction. DNA samples were precipitated in ethanol, resuspended in water, and kept in a cold room until used.

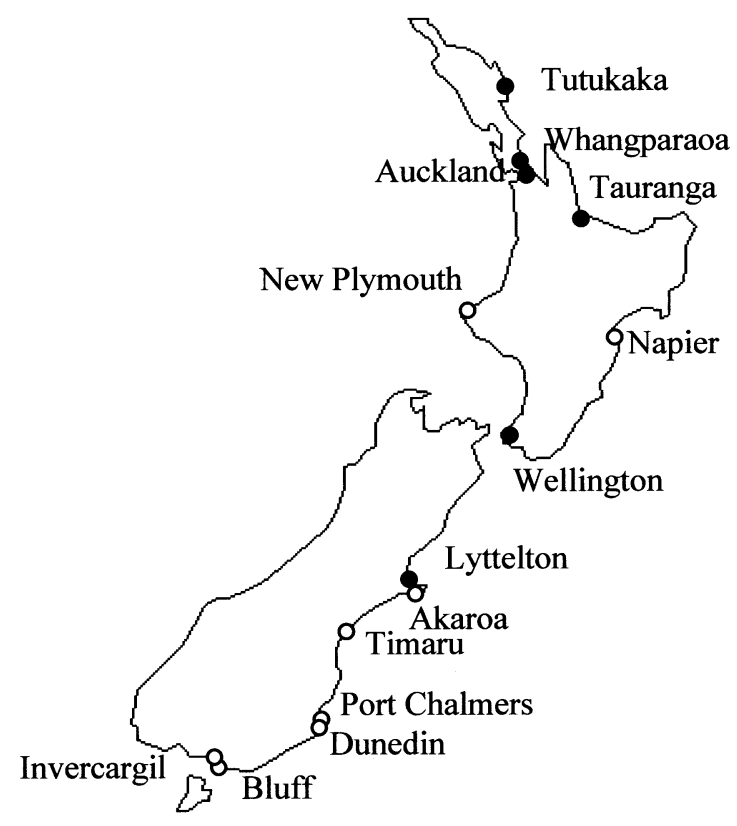

Fig. 1. Map of New Zealand islands showing sampling location. (๑) Localities in which Botryllus schlosseri colonies were collected; $(O)$ localities in which colonies were not found 
Microsatellite typing. Five Botryllus schlosseri microsatellites, BS-811 (Pancer et al. 1994), PB-29, PB-41, PB49, and PBC-1 (Stoner et al. 1997), were determined by PCR amplification following the suggested conditions. In Locus BS-811, 1 of the primers used by Stoner et al. (1997) was 28 bp upstream to the primer used by Pancer eration when comparing allele-size differences between localities. DNA was labeled with $\left[{ }^{35} \mathrm{~S}\right] \alpha \mathrm{dATP}$ in a $20 \mu \mathrm{l}$ reaction. Microsatellites were electrophoresed through $6 \%$ denaturing polyacrylamide gels (plate length $=50 \mathrm{~cm}$ ), using a known sequence of Blue Script SK plasmid (Stratagene) as a size marker. Several samples from different gels were re-run on the same gel to ensure unity of reading among the gels.

Data analysis. The different alleles and genotypes, as well as the observed heterozygosity, were determined directly from the autoradiographs. Expected heterozygosity and genetic distance were calculated following Nei's gene diversity and genetic distance, $D_{\mathrm{A}}$ (Nei 1987). Unbiased estimates of Hardy-Weinberg exact $\mathrm{p}$-values were computed by the Markov-chain method using GENEPOP, Version 3.1d (Raymond \& Rousset 1995). The significance level was determined after 20 batches and 1000 interactions each. Genetic et al. (1994) and by us. This has been taken into consid-

variance among populations, $F_{\mathrm{ST}}$, was calculated using the program ARLEQUIN, Version 1.1 (Schneider et al. 1997), and the significance level for the overall values was determined after 1023 permutations, and for the population pairwise $F_{\mathrm{ST}}$ values after 100 permutations. The population pairwise differentiation test (AMOVA) included 900000 Markov chain steps. An unrooted phylogram of population pairwise genetic distance was constructed using the neighbor-joining method (Saitou \& Nei 1987) as implemented in the program PHYLIP, Version 3.573c (Felsenstein 1993).

\section{RESULTS}

Allele distributions at each locus in each population of Botryllus schlosseri as well as observed and expected heterozygosity are presented in Tables 1 to 5 and the distribution at each locus in the North and the South Island populations is summarized in Fig. 2. A total of 55 different alleles were found in 5 tested microsatellites. Observed heterozygosity was lower than expected in most loci. A Hardy-Weinberg (HW) exact test for all loci and all populations revealed a p-value (HW equilibrium) of 0.0000 .

Allele distributions at each locus

Table 1. Botryllus schlosseri: BS-811 locus. Microsatellite allele-frequency distribution in New Zealand populations. $H_{0}, H_{\mathrm{e}}=$ observed and expected heterozygosity respectively

\begin{tabular}{|c|c|c|c|c|c|c|}
\hline & $\begin{array}{c}\text { Tutukaka } \\
(\mathrm{n}=20)\end{array}$ & $\begin{array}{l}\text { Whangparaoa } \\
\quad(\mathrm{n}=16)\end{array}$ & $\begin{array}{c}\text { Auckland } \\
(\mathrm{n}=37)\end{array}$ & $\begin{array}{c}\text { Tauranga } \\
(\mathrm{n}=18)\end{array}$ & $\begin{array}{l}\text { Wellington } \\
(\mathrm{n}=7)\end{array}$ & $\begin{array}{l}\text { Lyttelton } \\
(\mathrm{n}=33)\end{array}$ \\
\hline \multicolumn{7}{|l|}{ Allele size } \\
\hline 176 & & & & & & 0.03 \\
\hline 208 & & 0.03 & & & & 0.02 \\
\hline 210 & 0.10 & & & 0.05 & & 0.64 \\
\hline 212 & & 0.06 & & & & \\
\hline 214 & 0.78 & 0.50 & 0.82 & 0.38 & 0.79 & 0.17 \\
\hline 216 & & & 0.01 & & & \\
\hline 220 & 0.03 & & & & 0.07 & \\
\hline 234 & 0.03 & 0.13 & 0.04 & 0.22 & & \\
\hline 238 & & & 0.03 & 0.03 & & 0.05 \\
\hline 240 & 0.05 & 0.03 & & & & \\
\hline 242 & & & & 0.03 & & \\
\hline 244 & & 0.09 & 0.03 & & & \\
\hline 250 & & 0.09 & & & & \\
\hline 254 & & & 0.01 & & & \\
\hline 258 & & & 0.03 & & & \\
\hline 264 & & & & 0.05 & & \\
\hline 272 & & & & 0.05 & & 0.06 \\
\hline 282 & & 0.06 & 0.03 & 0.11 & 0.14 & 0.03 \\
\hline 288 & 0.03 & & & & & 0.02 \\
\hline 292 & & & & 0.08 & & \\
\hline No. of alleles & es 6 & 8 & 8 & 9 & 3 & 8 \\
\hline$H_{0}$ & 0.10 & 0.11 & 0.11 & 0.11 & $0.14(0.38)$ & 0.30 \\
\hline$H_{\mathrm{e}}$ & 0.38 & 0.68 & 0.32 & 0.78 & $0.35(0.41)$ & 0.55 \\
\hline \multicolumn{3}{|c|}{ No. of chimeras } & & 1 & & \\
\hline
\end{tabular}
revealed a few major and many rare alleles. In 4 loci (BS-811, $\mathrm{PB}$ 41, PB-49 and PBC-1), the South Island population of Lyttelton exhibited predominant alleles that were different from the North Island populations. $F_{\text {ST }}$ p-values were highly significant among all pairs togehter with Lyttelton. AMOVA differentiation tests between all populations revealed $\mathrm{p}$ (non-differentiation) $=0.0207 \pm 0.0058$, and the differentiation between all pairs of all populations showed that the South Island population of Lyttelton is the most distinct population. Hence, the significance level of each pair varies among repeated runs. Several runs showed significant differentiation between Lyttelton and some of the other populations; in repeated runs, however, the significance level of the same population pairs did not reach 0.05. However, in all runs, the significance level of any pair, including Lyttelton, was lower than 0.1. An unrooted neighborjoining tree is presented in Fig. 3. 

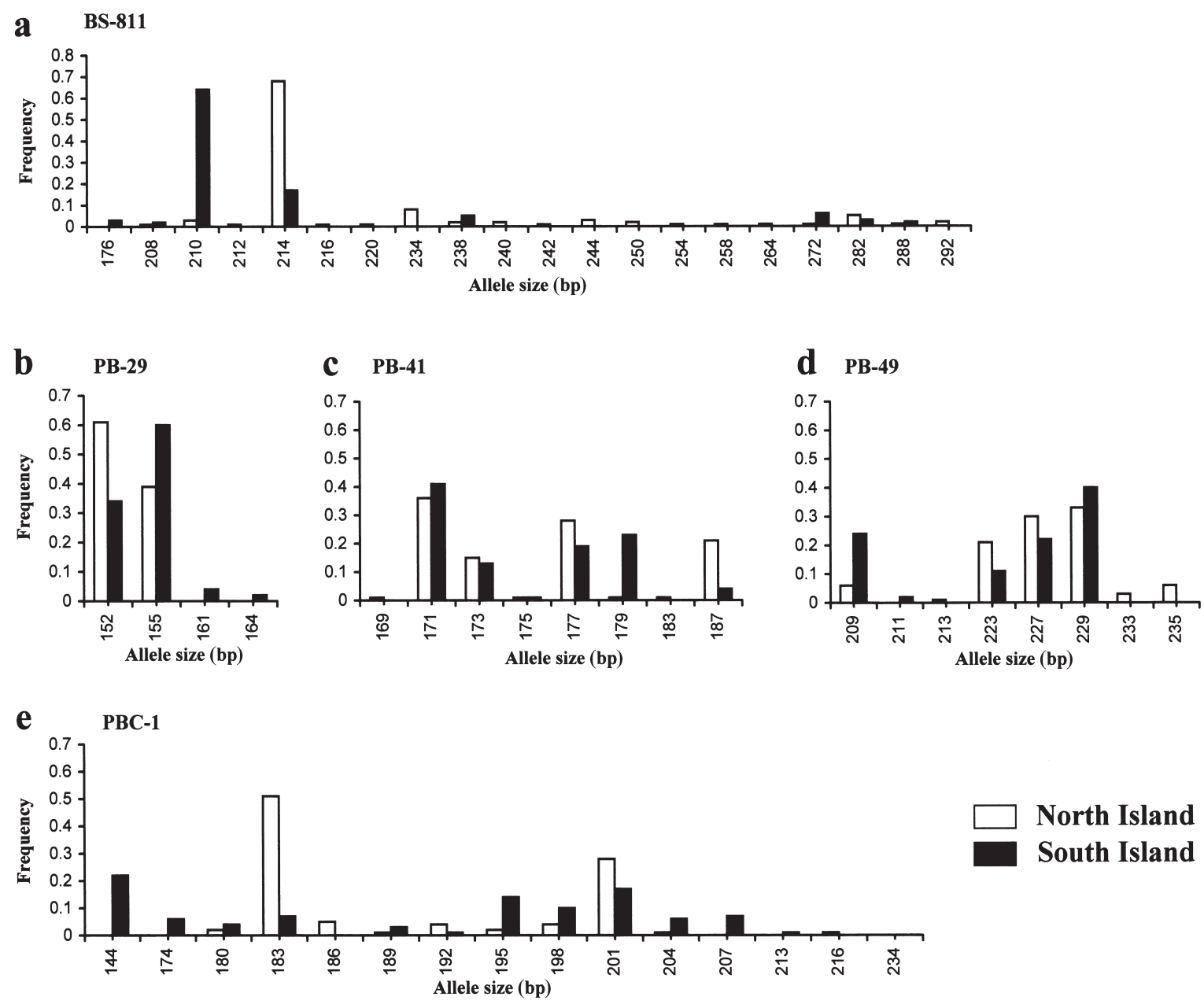

Fig. 2. Botryllus schlosseri. Allele-frequency histograms of 5 microsatellite loci: BS-811, PB-29, PB-41, PB-49 and PBC-1. Open bars: distribution for North Island; filled bars: distribution for South Island

Allogeneic contact between Botryllus schlosseri colonies can result in colony fusion (chimera formation). Chimeric individuals, showing 3 to 4 different bands per individual (Fig. 4) in a single microsatellite locus were found in all loci. Altogether, 16 chimeras were identified (Tables 1 to 5). This underestimates the level of chimerism as only samples that showed at least 3 bands were considered as chimeras, while some of the individuals that were defined as heterozygotes (sharing 2 bands) and some of the homozygotes may actually have been chimeras.

\section{DISCUSSION}

\section{Introduction of Botryllus schlosseri into New Zealand}

The introduction of Botryllus schlosseri, presumably a Mediterranean species, into New Zealand is believed to be associated with the European settlement in the Islands (Berrill 1950, Millar 1982). Massive ship movement between Europe and New Zealand has occurred during the last $150 \mathrm{yr}$. Considering the length of the trip and the low probability of B. schlosseri colonies surviving on ships' hulls all the way across the equator, it is reasonable to assume that the introduction of the species was not a common event. Settlement by ballast water is less probable because of the life history portrait of B. schlosseri, whereby planktonic larvae settlement takes place within $<1 \mathrm{~h}$ from hatching (Rinkevich et al. 1998 and references therein). Nowadays, however, during summer, B. schlosseri is widely spread in both North and South New Zealand Islands (Ralph \& Harley 1952, Skerman 1960, Poore 1968, Luckens 1976, Millar 1982).

It would be expected that a recent introduction of relatively few genotypes would be characterized by populations with low genetic variability (Avise 1994, 
and references therein). In theory, the reduction of gene diversity as a result of the reduction of population size (the bottleneck effect) should last for hundreds of thousands of generations (Nei et al. 1975). Moreover, although Botryllus schlosseri colonies are abundant during the summer (Millar 1982), this species disappears from many localities during the winter (Skerman 1958). During our field study (winter 1997), B. schlosseri populations were absent from shallow water in at least 2 North Island and 6 South Island localities. In some of these localities (such as in Portobello Marine Station) this species is abundant during the summer months (Portobello Ma-

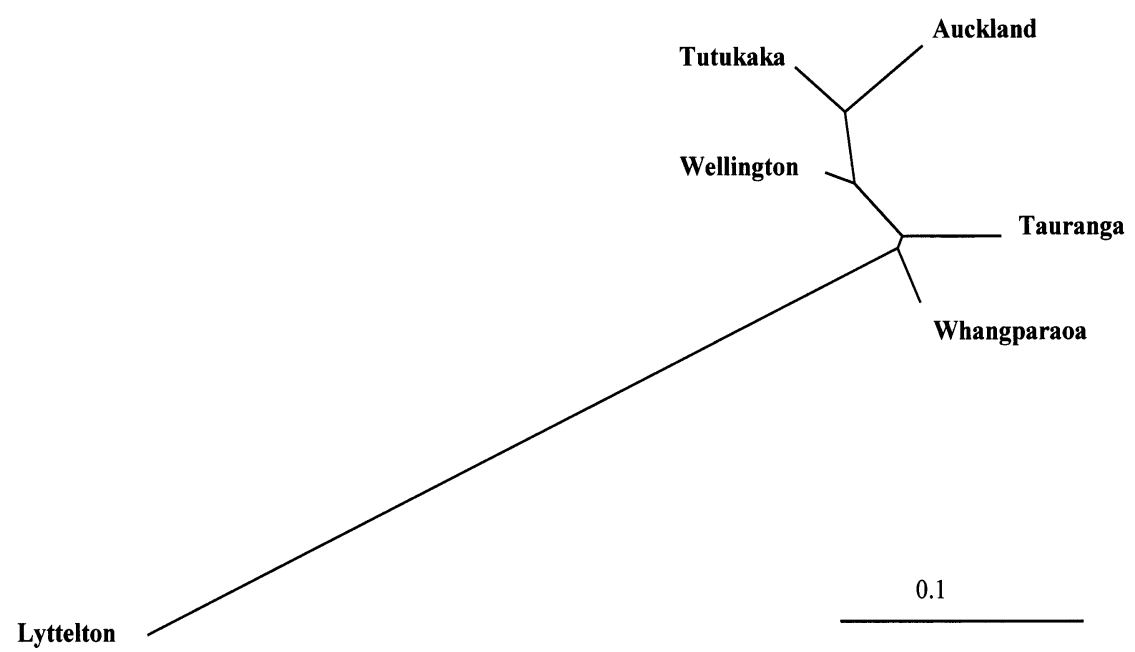

Fig. 3. Botryllus schlosseri. Unrooted neighbor-joining tree of sampled populations

rine Station staff unpubl. data). This may also be further expressed in lower genetic variability. The results of the present study, however, contradict the above expectations and reveal high numbers of alleles in most loci $(20,15,8,8$, and 4 alleles in BS-811, PBC-1, PB-41, PB-49, and PB-29 respectively). Similar results of a relatively high number of alleles per locus were found in another recently introduced population of $B$. schlosseri from Monterey Marina, California, USA (Stoner et al. 1997). Sixty individuals tested in Monterey possessed 3 to 17 alleles in these loci.

Although both western USA (Stoner et al. 1997) and New Zealand populations exhibited a high number of

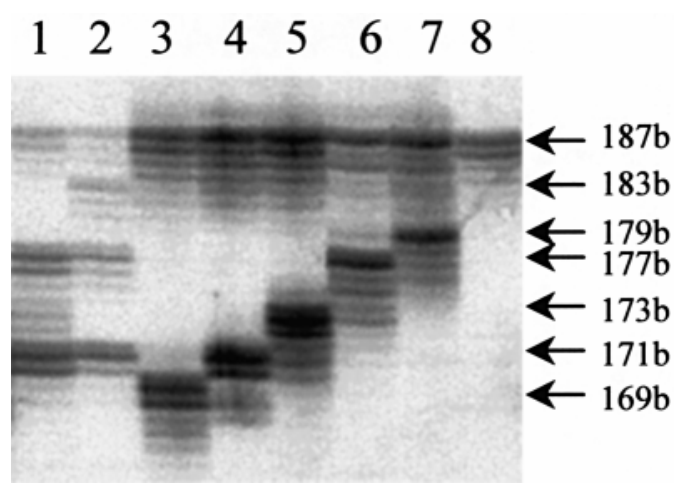

Fig. 4. Botryllus schlosseri. Autoradiograph of PB-41 microsatellite, showing 7 different alleles. Allele size was determined by strongest and highest band. Lanes 1 and 2 show chimeric colonies possessing 3 to 4 different bands. Genotypes of samples are: Sample 1, genotype chimera: 187/177/ 171; Sample 2, genotype chimera: 187/183/177/171; Sample 3, genotype heterozygote: 187/169; Sample 4, genotype heterozygote: 187/171; Sample 5, genotype heterozygote: 187/173; Sample 6, genotype heterozygote: 187/171; Sample 7, genotype heterozygote: 187/179; Sample 8, genotype homozygote: $187 / 187$ alleles, the most common allele at each site is different. This resulted in an extremely high calculated genetic distance between the 2 populations $\left(D_{\mathrm{A}}=0.91\right.$ for BS811, PB-29, PB-41 and PB-49 loci; Nei 1987). Of the 5 microsatellite loci studied, 3 (PB-29, PB-41 and PB-49) do not share a single allele between the 2 sites. In each of these 3 loci, the longest allele in New Zealand was shorter than the shortest allele in California. In New Zealand, allele-size ranged from 152-164, 169-187 and 209-235 for loci PB-29, PB-41 and PB-49 respectively, whereas in California, allele-sizes were 167-171, 195-210 and 236-262 for the same loci. In Locus BS-811, 30 different alleles were found but only 7 were shared between California and New Zealand. With regard to Locus PBC-1, while some allele-sizes overlapped between California and New Zealand, there was a shift in their sizes. In California, allele-sizes ranged between 190 and 235 bp (Stoner et al. 1997). In New Zealand the equivalent alleles ranged between 189 and $234 \mathrm{bp}$. Because of this discrepancy, we excluded Locus PBC-1 from the calculation of the genetic distance between the 2 populations and used only 4 loci. Hence, if the differences in size are genuine, the genetic distance is even higher.

The results, therefore, suggest different founders for Californian and New Zealand coasts. The bottleneck effect should cause an increase in the genetic distance between the populations (Nei 1987 and references therein). Notably, on Locus BS-811, the repertoire of alleles from the Mediterranean population of Israel included all 30 alleles that had been found in both California and New Zealand. The Israeli populations also possess 34 additional alleles (Paz 1999). These results further support the generally accepted idea that $B o-$ tryllus schlosseri originates from the Mediterranean Sea (Berrill 1950, Millar 1982). 
Table 2. Botryllus schlosseri: PB-29 locus. Microsatellite allele-frequency distribution in New Zealand populations

\begin{tabular}{|lcccccc|}
\hline \multicolumn{2}{|c}{$\begin{array}{c}\text { Tutukaka } \\
(\mathrm{n}=23)\end{array}$} & $\begin{array}{c}\text { Whangparaoa } \\
(\mathrm{n}=22)\end{array}$ & $\begin{array}{c}\text { Auckland } \\
(\mathrm{n}=37)\end{array}$ & $\begin{array}{c}\text { Tauranga } \\
(\mathrm{n}=29)\end{array}$ & $\begin{array}{c}\text { Wellington } \\
(\mathrm{n}=26)\end{array}$ & $\begin{array}{c}\text { Lyttelton } \\
(\mathrm{n}=50)\end{array}$ \\
\hline $\begin{array}{l}\text { Allele size } \\
152\end{array}$ & 0.63 & 0.48 & 0.74 & 0.64 & 0.48 & 0.34 \\
155 & 0.37 & 0.52 & 0.26 & 0.36 & 0.5 & 0.60 \\
161 & & & & & 0.02 & 0.04 \\
164 & & & & & & 0.02 \\
No. of alleles 2 & 2 & 2 & 2 & 3 & 4 \\
$H_{0}$ & 0.48 & 0.68 & 0.46 & 0.45 & 0.62 & 0.60 \\
$H_{\mathrm{e}}$ & 0.47 & 0.50 & 0.38 & 0.46 & 0.52 & 0.52 \\
No. of chimeras & & & & & \\
\hline
\end{tabular}

Table 3. Botryllus schlosseri: PB-41 locus. Microsatellite allele-frequency distribution in New Zealand populations

\begin{tabular}{|c|c|c|c|c|c|c|}
\hline & $\begin{array}{c}\text { Tutukaka } \\
(\mathrm{n}=18)\end{array}$ & $\begin{array}{c}\text { Whangparaoa } \\
\quad(\mathrm{n}=18)\end{array}$ & $\begin{array}{c}\text { Auckland } \\
(\mathrm{n}=29)\end{array}$ & $\begin{array}{c}\text { Tauranga } \\
(\mathrm{n}=24)\end{array}$ & $\begin{array}{c}\text { Wellington } \\
(\mathrm{n}=20)\end{array}$ & $\begin{array}{l}\text { Lyttelton } \\
(\mathrm{n}=50)\end{array}$ \\
\hline \multicolumn{7}{|l|}{ Allele size } \\
\hline 169 & & & 0.02 & 0.02 & & \\
\hline 171 & 0.42 & 0.29 & 0.24 & 0.33 & 0.58 & 0.41 \\
\hline 173 & 0.14 & 0.18 & 0.16 & 0.18 & 0.05 & 0.13 \\
\hline 175 & & & & & 0.03 & 0.01 \\
\hline 177 & 0.33 & 0.44 & 0.33 & 0.16 & 0.13 & 0.19 \\
\hline 179 & & & & & 0.03 & 0.23 \\
\hline 183 & & 0.03 & & & & \\
\hline 187 & 0.11 & 0.05 & 0.26 & 0.31 & 0.20 & 0.04 \\
\hline No. of allele & es 4 & 5 & 5 & 5 & 6 & 6 \\
\hline$H_{0}$ & 0.72 & 0.44 & 0.69 & 0.71 & 0.70 & 0.84 \\
\hline$H_{\mathrm{e}}$ & 0.68 & 0.69 & 0.74 & 0.74 & 0.60 & 0.72 \\
\hline \multicolumn{2}{|c|}{ No. of chimeras } & 1 & & 3 & & 1 \\
\hline
\end{tabular}

Table 4. Botryllus schlosseri: PB-49 locus. Microsatellite allele-frequency distribution in New Zealand populations

\begin{tabular}{|c|c|c|c|c|c|c|}
\hline & $\begin{array}{c}\text { Tutukaka } \\
\text { (n }=25\end{array}$ & $\begin{array}{l}\text { Whangparaoa } \\
\qquad(\mathrm{n}=14)\end{array}$ & $\begin{array}{c}\text { Auckland } \\
(\mathrm{n}=38)\end{array}$ & $\begin{array}{c}\text { Tauranga } \\
(\mathrm{n}=27)\end{array}$ & $\begin{array}{c}\text { Wellington } \\
(\mathrm{n}=27)\end{array}$ & $\begin{array}{l}\text { Lyttelton } \\
(\mathrm{n}=47)\end{array}$ \\
\hline \multicolumn{7}{|l|}{ Allele size } \\
\hline 209 & & & 0.03 & 0.09 & 0.15 & 0.24 \\
\hline 211 & & & & & & 0.02 \\
\hline 213 & & 0.04 & & 0.04 & & \\
\hline 223 & 0.12 & 0.29 & 0.17 & 0.41 & 0.11 & 0.11 \\
\hline 227 & 0.34 & 0.32 & 0.34 & 0.22 & 0.29 & 0.22 \\
\hline 229 & 0.52 & 0.21 & 0.37 & 0.19 & 0.31 & 0.40 \\
\hline 233 & & 0.14 & & 0.06 & & \\
\hline 235 & 0.02 & & 0.09 & & 0.15 & \\
\hline No. of allele & es 4 & 5 & 5 & 6 & 5 & 5 \\
\hline$H_{0}$ & 0.56 & 0.43 & 0.47 & 0.33 & 0.78 & 0.57 \\
\hline$H_{\mathrm{e}}$ & 0.60 & 0.75 & 0.71 & 0.73 & 0.76 & 0.72 \\
\hline \multicolumn{4}{|c|}{ No. of chimeras } & & 1 & \\
\hline
\end{tabular}

\section{Inter-island comparisons}

Different founder genotypes probably established the New Zealand North and South Islands populations. Moreover, it seems that gene flow between the 2 islands is limited. This is best expressed by Locus BS-811. Allele $214 \mathrm{bp}$ is probably the founder allele of this locus in the North Island populations, appearing in high frequencies (38 to $82 \%$; Table 1 ) in all 5 populations studied. Each of the other 18 alleles scored on this locus in the North Island population was much less abundant (Table 1, Fig. 2a). In the South Island, the $214 \mathrm{bp}$ allele frequency was only $17 \%$ and the predominant allele was $210 \mathrm{bp}(64 \%)$. The $210 \mathrm{bp}$ allele appeared at low frequencies (5 to $10 \%$ ) in only 2 North Island populations.

With regard to Locus PB-41 (Table 3), the second most frequent allele in Lyttelton (179 bp, $23 \%$ ) was found in only 1 population of the North Island where it was rare (3\%). Similarly, in Locus PBC-1 (Table 5), the most frequent allele (183 bp; 37 to $66 \%$ ) of the North Island populations was rare $(7 \%)$ in the South Island, whereas the common allele in the South Island, 144 bp (22\%), was only found on this island. $F_{\mathrm{ST}}$ p-values were highly significant among pairs of each of the North Island and Lyttelton populations. Genetic distance between both islands is relatively high $\left(D_{\mathrm{A}}=\right.$ 0.22 ; Nei 1987). This resulted from the different allelic distribution patterns between Lyttelton and the North Island populations (Fig. 2).

The consistent predominant appearance of 1 of the alleles in each locality is uniquely characteristic to introduced populations. This point is further illustrated by the following example. Locus BS-811 was tested in another recently introduced population of Monterey, California (Stoner et al. 1997), and 
in Mediterranean populations of Israel, which presumably were the origin of Botryllus schlosseri. In California, another predominant allele has been scored (264 bp, equivalent to $236 \mathrm{bp}$ in this study) with a frequency of approximately $30 \%$. In the Israeli populations, however, none of the 64 alleles scored on this locus had a frequency exceeding $8 \%$ (Paz 1999). These results support the conclusion that a limited number of different individual colonies have established each one of the worldwide distributed B. schlosseri populations.

\section{Heterozygote deficiency}

Loci BS-811, PB-49, and PBC-1 reveal cases of significant heterozygote deficiency ( $p \ll 0.001$ ). HW exact tests for all loci and all populations revealed a p-value (HW equilibrium) of 0.0000. Such deviations from expected levels may reflect a genuine biological phenomenon characteristic to Botryllus schlosseri. A similar outcome of heterozygote deficiency was found in all tested loci of the Monterey population, California (Stoner et al. 1997), and in the BS-811 locus of Israeli populations (Pancer et al. 1994, Paz 1999). Heterozygote deficiency that is recorded repeatedly on several loci on individuals collected from different localities by different laboratories and at different times further supports the assumption of a genuine phenomenon.

Table 5. Botryllus schlosseri: PBC-1 locus. Microsatellite allele-frequency distribution in New Zealand populations

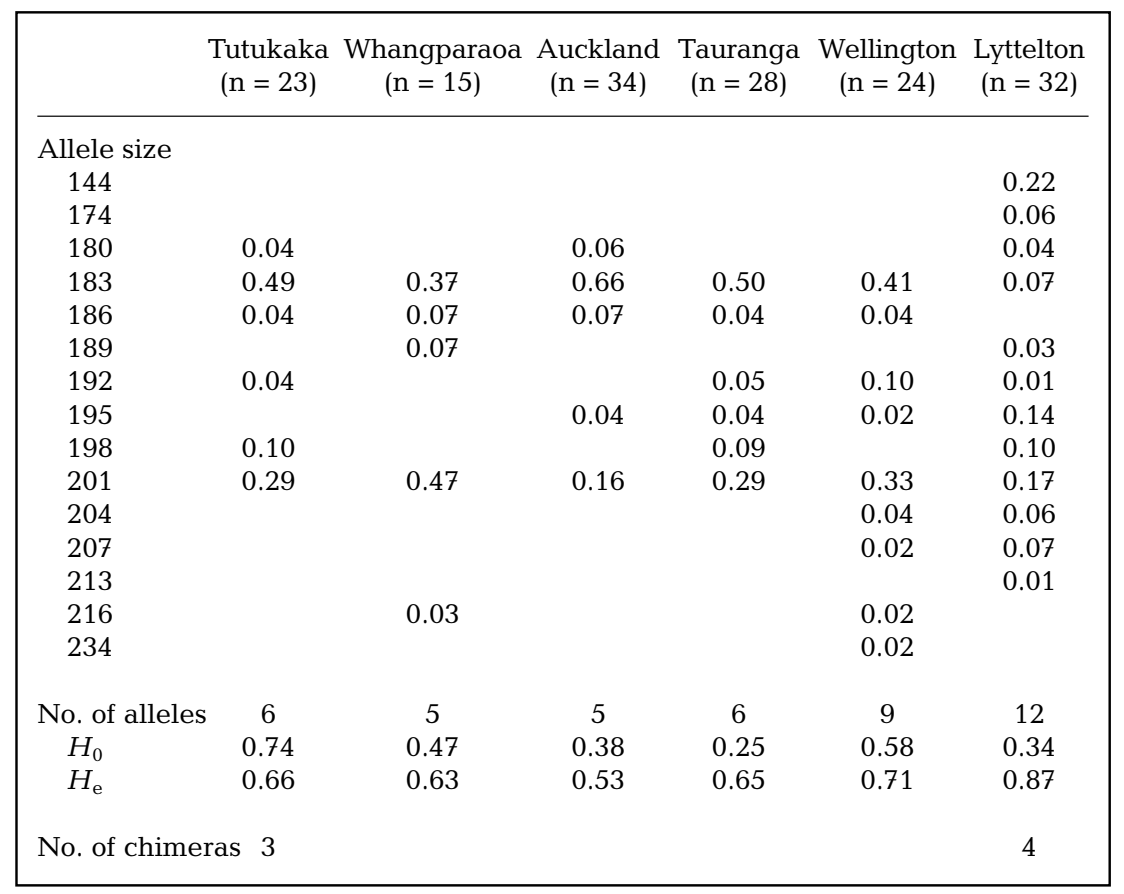

Inbreeding or non-random mating is a probable explanation of the deficiency. Heterozygote deficiency can also arise in substructured populations, consisting of subpopulations in which gene flow is somewhat restricted (Chakraborty \& Jin 1992). Although Botryllus schlosseri colonies are hermaphrodites, sperm release from gravid colonies does not start until about 1 to $2 \mathrm{~d}$ after ovulation, effectively preventing selffertilization (Yund et al. 1997). Grosberg \& Quinn (1986) showed in field experiments, on the other hand, an aggregated settlement of sibling $B$. schlosseri planktonic larvae. Such aggregations may form smallscale subpopulations, a situation that promotes mating between sibling colonies (Sabbadin 1978, Grosberg \& Quinn 1986, Rinkevich et al. 1998).

\section{Natural chimerism}

Many marine invertebrates undergo natural allogeneic interactions which are followed by the state of chimerism (Buss 1982). Allogeneic contacts between Botryllus schlosseri colonies may result either in colony fusion (chimera formation) or in an inflammatory reaction (rejection). Laboratory and field experiments documented that somatic- and germ-cell parasitism are both common outcomes of chimerism (Pancer et al. 1995, Stoner \& Weissman 1996, Stoner et al. 1999). By using microsatellite markers on 2 mo old chimeras, Stoner \& Weissman (1996) have shown that while chimeras may exhibit a uniform color and morphological patterns, tissues throughout the entire chimera may exhibit both genotypes. Although most studies on B. schlosseri chimerism have been performed in the laboratory (Rinkevich 1996), a recent study (Stoner \& Weissman 1996) also documented the existence of chimerism in natural populations. There is no study, however, that reveals the chimeras' frequencies in the field.

In the present study, efforts were made to avoid collection of seemingly chimeric colonies in the field. Nonetheless, while examining the genetic pattern distribution of the 5 microsatellite loci, we found 16 chimeras $(>8 \%$ of all colonies), each characterized, by 3 to 4 bands on the autoradiographs (Tables 1 to 5, Fig. 4). Chimera frequencies in the Lyttelton popu- 
lation reach $14 \%$. This calculation underestimated the level of natural chimerism, since (1) colonies that showed morphological evidence of chimeras were not collected, and (2) colonies defined as heterozygotes (sharing 2 bands), and probably also some of the homozygotes, could actually be chimeras. The genetic evidence for each chimera is documented in only 1 of the examined loci. More microsatellite loci will probably increase the number of scored chimeras.

The evolutionary significance of chimerism is not yet clear. Theoretically, natural chimeras, as compared with individual colonies, may have a greater store of genetic variability and hence a wider range of physiological qualities and characteristics (Rinkevich \& Weissman 1992, Rinkevich 1996). The underestimated level of 8 to $14 \%$ chimeric individuals in the field indicates that this phenomenon is substantially important in the life history of Botryllus schlosseri. The level of chimerism, at any sampling time, reflects fusion frequencies (correlated with colony densities) a few months prior to the date of collection. A sampling program that analyzes chimerism levels in dense and sparse populations during the year, as well as in original versus newly established and peripheral populations, will help in revealing the significance of this phenomenon in nature.

The present study aimed to reveal the genetic characterization of a successful cosmopolitan urochordate. Different populations of Botryllus schlosseri exhibit significant variation in morphological characteristics, as well as life history patterns and genetic background. Additional studies are required to further analyze central and peripheral populations for the formulation of a comprehensive genetic structure of this species.

Acknowledgements. Thanks are due to R. Babcock for hospitality and to C. Battershill, B. Dickson, J. Gardner, and K. Probert for information regarding Botryllus schlosseri in New Zealand. The study was supported by the US-Israel Binational Science Foundation and by the Minerva Center for Marine Invertebrates Immunology and Developmental Biology. We would like to express our regards to the unknown referees, whose helpful suggestions contributed significantly to this study.

\section{LITERATURE CITED}

Avise JC (1994) Molecular markers, natural history and evolution. Chapman \& Hall, New York

Bastrop R, Jurss K, Sturmbauer C (1998) Cryptic species in marine polychaetes and their independent introduction from North America to Europe. Molec Biol Evolut 15: 97-103

Berrill NJ (1950) The Tunicata. Bernard Quaritch Ltd., London

Buss LW (1982) Somatic cell parasitism and the evolution of somatic tissue compatibility. Proc Natl Acad Sci USA 79: $5337-5341$
Carlton JT, Geller JB (1993) Ecological roulette: the global transport of nonindigenous marine organisms. Science 261:78-82

Chakraborty R, Jin L (1992) Heterozygote deficiency, population substructure and their implications in DNA fingerprinting. Hum Genetics 88:267-272

Felsenstein J (1993) PHYLIP (phylogeny inference package) Version 3.5c. Distribution by the author. Department of Genetics, University of Washington, Seattle

Graham DE (1978) The isolation of high molecular weight DNA from whole organisms or large tissue masses. Analyt Biochem 85:609-613

Gray AJ (1986) Do invading species have definable genetic characteristic? Phil Trans R Soc Lond Ser B 314:655-674

Grosberg RK, Quinn JF (1986) The genetic control and consequences of kin recognition by the larvae of a colonial marine invertebrate. Nature 322:456-459

Lambert CC, Lambert G (1998) Non-indigenous ascidians in southern California harbors and marinas. Mar Biol 130: 675-688

Luckens PA (1976) Settlement and succession on rocky shores at Auckland, North Island, New Zealand. Mem NZ Oceanogr Inst 70:1-64

Millar RH (1982) The marine fauna of New Zealand: Ascidiacea. Mem NZ Oceanogr Inst 85:1-116

Nei M (1987) Molecular evolutionary genetics. Columbia University Press, New York

Nei M, Maruyama T, Chakraborty R (1975) The bottleneck effect and genetic variability in populations. Evolution 29: $1-10$

Pancer Z, Gershon H, Rinkevich B (1994) Direct typing of polymorphic microsatellites in the colonial tunicate Botryllus schlosseri (Ascidiacea). Biochem Biophys Res Commun 203:646-651

Pancer Z, Gershon H, Rinkevich B (1995) Coexistence and possible parasitism of somatic and germ cell lines in chimeras of the colonial urochordate Botryllus schlosseri. Biol Bull 189:106-112

Paz G (1999) Genetic variation among populations of a cosmopolitan urochordate along the Israel Coast. Israel J Zool 45:319

Poore GCB (1968) Succession of wharf-pile fauna at Lyttelton, New Zealand. NZ J Mar Freshw Res 2:577-590

Ralph PM, Harley DE (1952) The settling and growth of wharf-pile fauna in Port Nicholson, Wellington, New Zealand. Zool Publs Vict Univ Coll 19:1-22

Raymond M, Rousset F (1995) GENEPOP (Version 1.2): population genetics software for exact tests and ecumenicism. J Hered 86:248-249

Rinkevich B (1996) Bi- versus multichimerism in colonial urochordates: a hypothesis for links between natural tissue transplantation, allogenetics and evolutionary ecology. Exp Clin Immunogenetics 13:61-69

Rinkevich B, Weissman IL (1992) Chimeras vs genetically homogeneous individuals: potential fitness costs and benefits. Oikos 63:119-124

Rinkevich B, Porat R, Goren M (1998) Ecological and life history characteristics of Botryllus schlosseri (Tunicata) populations inhabiting undersurface shallow water stones. PSZN I: Mar Ecol 19:129-145

Sabbadin A (1978) Genetics of the colonial ascidian Botryllus schlosseri. In: Battglia B, Beardmore J (eds) Marine organisms. Plenum Press, New York, p 195-209

Saitou N, Nei M (1987) The neighbor-joining method: a new method for reconstructing phylogenetic trees. Molec Biol Evolut 4:406-425

Schneider S, Kueffer JM, Roessli D, Excoffier L (1997) ARLE- 
QUIN, Version 1.1: a software for population genetic data analysis. Genetics and Biometry Laboratory, University of Geneva

Skerman TM (1958) Marine fouling at the port of Lyttelton. NZ Sci 1:224-257

Skerman TM (1960) Ship-fouling in New Zealand waters: a survey of marine fouling organisms from vessels of the coastal and overseas trades. NZ Sci 3:620-648

Stoner DS, Weissman IL (1996) Somatic and germ cell parasitism in colonial ascidian: possible role for a highly polymorphic allorecognition system. Proc Natl Acad Sci USA 93:15254-15259

Editorial responsibility: Otto Kinne (Editor),

Oldendorf/Luhe, Germany
Stoner DS, Quattro JMQ, Weissman IL (1997) Highly polymorphic microsatellite loci in the colonial ascidian Botryllus schlosseri. Molec Mar Biol Biotechnol 6:163-171

Stoner DS, Rinkevich B, Weissman IL (1999) Heritable germ and somatic cell lineage competitions in chimeric colonial protochordates. Proc Natl Acad Sci USA 96:9148-9153

van Name WG (1945) The North and South American ascidians. Bull Am Mus Nat Hist 84:1-476

Yund PO, Marcum Y, Stewart-Savage J (1997) Life history variation in a colonial ascidian: broad-sense heritabilities and tradeoffs in allocation to asexual growth and male and female reproduction. Biol Bull 192:290-299

Submitted: March 24, 2000; Accepted: June 20, 2000 Proofs received from author(s): December 12, 2000 